4 Sayago, P. ' ; Juncosa, F ${ }^{1}$; Albarracín Orio, A. ${ }^{1}$; Paccioretti, M. ${ }^{2}$; Gonzalez, V..; Otero, $5 \quad$ M.L. ${ }^{2}$; Ducasse D.A ${ }^{2 *}$.

\section{Development of an innovative in vitro method for mass production of Verticillium dahliae microsclerotia}

${ }^{1}$ IRNASUS, Catholic University of Córdoba, CONICET, School of Agronomy, Córdoba,

Argentina. ${ }^{2}$ Institute of Plant Pathology, Center for Agricultural Research, National Institute of Agricultural Technology, Córdoba, Argentina.

\section{Correspondence}

\section{* ducasse.daniel@inta.gob.ar}

\section{Abstract}

The soil-borne fungal plant pathogen Verticillium dahliae can infect more than 300 plant species including important economic crops, causing great economic loses. V. dahliae can persist and survive more than 14 years in the soil by resistance structures, known as microsclerotia, which constitute the primary inoculum in the field. In vitro mass production of microsclerotia is essential for performing many pathological assays. Nevertheless to harvest the microsclerotia is not an easy task and several protocols have been described although none of them is completely satisfying for different reasons. here we present a new protocol that is reproducible, robust, simple and fast allows to overcome the difficulties for obtaining massive amounts of microsclerotia. In summary, we developed a new culture medium that we called Pluronic Potato Medium (PPM) because it is essentially potato dextrose media with the hydrogel, Pluronic F127 as a solidifying agent. The microsclerotia collected in form PPM were infectious in tomato plants were 
they were able to reproduce the disease and we recovered and quantitated V. dahliae in infected plants.

Keywords Verticillum dahliae, microsclerotia, inoculum, mass production, pluronic

\section{Introduction}

Verticillium dahliae Kleb. (Klebahn, 1913) is a soil-borne plant pathogen with a wide host range that includes many economically important crops worldwide (Bhat \& Subbarao, 2007). Difficulties in managing and controlling the pathogen mainly arise from its capacity of forming microsclerotia, resistant structures able to survive more than 14 years (Short et al., 2015; Fan et al., 2017) and from the wide host range composed of more than 300 species between woody and herbaceous plants in general, which makes very difficult to apply cultural practices in the field such as crop rotation (Fradin \& Thomma, 2006). Apart from the already mentioned microsclerotia, $V$. dahliae produces, inside of the xylem vessels of the infected hosts, short-term persistence conidia that are responsible of the vascular colonization (Schnathorst, 1981).

Microsclerotia (MS) are resistance structures originated from condensed vegetative hyphae that intertwine and aggregate one another (Chet \& Henis, 1975). In these multicellular structures, melanin is deposited in the inter-hyphal spaces while the peripheral microsclerotic cells are destroyed by autolysis, leaving the thickened cell wall surrounded by melanin as a protective barrier of the core cells (Keykhasaber et al., 2018; Xiong et al., 2016). Survival of MS is very important in the $V$. dahliae disease cycle, because primary infections are caused by their germination that is stimulated by host root exudates (Klosterman et al., 2009) and the incidence of the disease will be related to the amount of inoculum (MS) in the soil (Mol, 1995; López-Escudero \& Blanco-López, 2007). 
51 To understand the pathosystem (host- $V$. dahliae) and develop appropriate control

52 measures, reproducing the natural conditions of the infection is essential (López-

53 Escudero \& Blanco-López, 2007), which raises the need to have a soil naturally infested

with MS or produce an in vitro mass to inoculate the soil and the latter is not an easy task.

Numerous culture media have been reported to achieve MS production such as ethanol agar (EA) medium (Nadakavukaren, \& Horner, 1959), modified sodium poly spectory agar (APSM) (Butterfield \& DeVay, 1977; López-Escudero \& Blanco-López, 2007), potato dextrose agar (PDA) medium covered with a cellophane disc (Devay et al.,1974; López-Escudero et al., 2006), senescent potato stems (Harrison \& Isaac, 1969), modified Czapek Dox agar (MCDX) medium (Hawke \& Lazarovits, 1994), minimal medium (MM) covered with a cellophane disc (Botseas \& Rowe, 1994), green potato stems (Mol, 1995), basal agar medium (BM) covered with a cellulose membrane disc (Neumann \& Dobinson, 2003), SSN (Malandraki et. al, 2008) and modified sodium polypetate (MSP) (Varo et al., 2016). The main inconveniences of these methods can be summarized as it follows; many of them have been developed for specific isolates (Hu et al., 2013), when the culture is done in liquid media normally the times of growing and development of MS are extremely long and finally, when the culture is done on solid media although times are shortened, it is very hard to recover the MS.

Here we report an innovative method for the production of MS of Verticillium dahliae Kleb. in vitro based on a hydrogel, Pluronic F127 (Bercea et al., 2011; Gwon et al., 2018; Wu et al., 2018), highlighted for its striking thermoreversible feature that allows thermally induced phase separation (TIPS) (Qiu et al., 2008) simplifying the production and recovery of the MS in short periods of time. 


\section{$76 \quad$ Material and methods}

\section{$77 \quad$ Fungal material}

For this study a non-defoliant native strain of Verticillium dahliae Kleb. was used. The pathogen was isolated from olive plants, from one of the most important olive growing regions of Argentina. $V$. dahliae was cultured for 15 days at $24{ }^{\circ} \mathrm{C}$ in the dark in potato dextrose agar (PDA) medium.

\section{Preparation of Pluronic Potato Medium (PPM) for production of microsclerotia} Pluronic F-127 (P2443, Sigma-Aldrich, St. Louis, United States) was added to the potato dextrose broth (PDB) to a final concentration of $25 \%(\mathrm{w} / \mathrm{v})$. This medium was kept at $4{ }^{\circ}$ $\mathrm{C}$ for $10 \mathrm{~h}$ to favor polymer melting and after this period, it was autoclaved.

Pluronic Potato Medium (PPM) was left for $48 \mathrm{hr}$ at $4{ }^{\circ} \mathrm{C}$ to allow it to change to liquid phase. After that, it was poured into Petri dishes $(55 \times 15 \mathrm{~mm})$ and left to settle at room temperature for 15 min until solidification.

An agar plug containing $V$. dahliae mycelium was placed in the center of the plate and allowed to grow at $24{ }^{\circ} \mathrm{C}$ for 15 days in the dark.

\section{Obtaining and counting microsclerotia}

Based upon the thermoreversible properties of the Pluronic F127, after $V$. dahliae reached its maximum growth, PPM dishes were incubated at $4{ }^{\circ} \mathrm{C}$ to facilitate the phase change of the medium from solid to liquid and perform a TIPS.

Once the PPM was completely liquid, the harvest of MS was carried out with a vacuum filtration apparatus Millipore Sigma (Sigma-Aldrich ${ }^{\circledR}$, St. Louis, USA). Sterile water at $2{ }^{\circ} \mathrm{C}$ was used to facilitate the process. Afterwards, the filter paper with the MS collected was placed in a sterile tube containing $30 \mathrm{ml}$ of sterile physiological solution to favor MS 
conservation and viability. Then, $1 \mathrm{ml}$ of the suspension was serially diluted in order to

102

103

104 count viable MS in PDA dishes. The percentage of MS germination was monitored considering that each generated fungal colony arose from a single MS.

\section{Feasibility and pathogenicity tests of recovered microsclerotia}

Tomato seeds (Lycopersicon esculentum Mill.) Cv Moneymaker, V. dahliae susceptible, were sown in vitro (Sarmiento-Villamil et al., 2018). Tomato seeds were surface sterilized using a 70\% ethanol solution for 2 minutes, followed by a 3\% sodium hypochlorite solution for 5 minutes. Subsequently, they were rinsed with sterile water 3 times and allowed to dry for about $5 \mathrm{~min}$ in a laminar flow hood. They were then placed in a flatbottomed test tube containing modified Strullu-Romand (MSR) culture medium (Declerck, 2005), using 3 g/l Phytagel as solidifying agent (Sigma-Aldrich ${ }^{\circledR}$, St. Louis, USA.) and then incubated under $16 \mathrm{~L}: 8 \mathrm{D}$ photoperiod at $27^{\circ} \mathrm{C}$.

When the tomato seedlings had three true leaves, 15 plants were inoculated with $500 \mu 1$ of a suspension of $1000 \mathrm{MS}_{\mu 1}^{-1}$. Ten plants were inoculated with $500 \mu 1$ of sterile distilled water as controls.

\section{In plant detection of $V$. dahliae Kleb.}

Detection and quantification of $V$. dahliae in infected plants was performed by polymerase chain reaction (PCR) technique according to the protocol described by Mercado-Blanco and co-workers (Mercado-Blanco et al. 2001).

Twenty-five days post inoculation (dpi) with $V$. dahliae, total genomic DNA was extracted from three $\mathrm{cm}$ of stem, just above the neck of tomato plantlets. DNA was purified by CTAB method (Lee et al., 1988; Wu et al., 2001) and the concentration was measured using a NanoDrop®-ND 1000 UV-Vis spectrophotometer (NanoDrop Technologies, Wilmington, USA). 
126 Nested PCR reaction was set according to a previously described protocol (Mercado-

127 Blanco et al., 2001). Purified DNA from $V$. dahliae mycelium was used as a positive control and DNA from non-infected tomato plants were used as negative control. In addition, q-PCR technique was performed according to Bilodeau et al., (2012) to confirm the presence of $V$. dahliae infecting tomato plants.

\section{Results}

$V$. dahliae grew and produced microesclerotia both in PDA and in PPM media. After 15 days MS formation was observed in both culture media (Fig. 1). While MS could not be extracted from PDA medium due to the agar, MS formed on PPM were easily harvested and the yield was $1 \times 10^{6} \mathrm{MS} \mathrm{ml}^{-1}$. We observed that $100 \%$ of the MS were able to form

137 fungal colonies (Fig. 2).

Tomato plants inoculated with MS produced in PPM showed wilt and root necrosis at 25 dpi whereas the control plants developed normally.

These symptoms were confirmed as caused by $V$. dahliae by nested PCR and qPCR reactions (Figure 3). As seen in photo 3, diseased plants presented a DNA band of the expected size $(824 \mathrm{bp})$ equal to that obtained from the positive control. No amplification products were obtained from negative controls.

\section{Discussion}

Research on the development of the disease cycle, epidemiology, host resistance and biological control are fundamental in order to develop new eco-friendly alternatives for managing crop diseases. (Enebe \& Babalola, 2019; Sánchez-Martín \& Keller, 2019).

In this scenario, $V$. dahliae is a particularly challenging pathogen, due to its wide host 
151 active inoculum for long periods(Wheeler \& Johnson, 2016).

152 Recent studies point out that stimulation of MS by host roots exudates is essential for the occurrence of natural infections by $V$. dahliae. Consecuently, in order to understand the role of pathogen survival and the development of the disease under field conditions, MS must be used as a source of inoculum (Hu et al., 2013; Varo et al., 2016).

156 Several methods for $V$. dahliae MS production have been reported with different advantages and disadvantages. Two factors are essential in the metabolic process of forming MS from mycelium. One is the carbon source and the other is the oxygen levels that must be supplied in an adequate and constant flux (Jackson \& Payne, 2016). With regards to the carbon source, two of the most commonly used culture media for MS production, propose polipectate, APSM (Butterfield \& DeVay, 1977; López-Escudero \& Blanco-López, 2007) and MSP (Varo et al., 2016). Other two media, Czapek Dox (Hawke \& Lazarovits, 1994) and SSN (Malandraki et al., 2008) use glucose and sucrose as carbon source. In order to fulfill the requirement of a constant oxygen delivery to the fungal cells without generating stress (Jeong et al., 2006), and considering the long period of incubation (28 days) the authors proposed to keep the media in permanent agitation and darkness (Varo et al., 2016). Additionally, these media present a diverse basal salts concentration, antibiotics and $\mathrm{pH}$ in their composition, causing a diverse effect on MS production (Hu et al., 2013).

The media presented in our work, the PPM media, uses dextrose and potato starch from potato infusion as carbon sources. We decided to use these two ingredients because they are the essential components of PDA medium, that is commonly used to grow and keep $V$. dahliae cultures. The main inconvenient of PDA for producing $V$. dahliae MS is the agar that prenvents an efficient harvesting of them as they grow plugged in the medium. 
175 This difficulty was absolutely overcomed by using a thermoreversible hydrogel as

176 Pluronic F-127 as a solidifying agent in PPM medium.

177 Poloxamer or Pluronics hydrogels are triblock copolymers (nonionic, polyoxyethylenepolyoxypropylene-polyoxyethylene (PEO-PPO-PEO)) that have multiple pharmaceutical applications (Bohorquez et al., 1999). A widely explored member of this family is Pluronic F127, which has 1200 kDa PPO units and 70\% PEO content (Wang et al., 2019).

The most striking feature of this hydrogel is that, due to its composition, it shows transformations as a function of temperature changes. This characteristic of thermoreversible gel is useful in concentrations higher than or equal to $20 \%$. Cold temperatures cause the gel to go from solid to liquid state, while remaining solid at room temperature (Akash \& Rehman, 2015). These characteristics of appropriate hydrophilic / lipophilic balance, high molecular weight, thermos-reversibility and lower mechanical strength allow for a high extraction capacity in aqueous phase (Lv et al. 2007) by TIPS (Qiu et al., 2008). Hydrogels such as Pluronic F127 have been used mainly as detergents, stabilizers, foaming agents and emulsifiers in the field of biomedicine, in tissue engineering and pharmacology (Bercea et al., 2011; Gwon et al., 2018; Wu et al., 2018).

Recently, they have been used in studies of interactions between plant parasitic nematodes and plants (Li et al., 2019).

The main advantages of a massive production of $V$. dalihae MS using the PPM media and the methodology here described are the short time elapsed from inoculating the mycelium to the moment of collecting the MS, the minimal physical space needed for producing MS and that the use of a permanent agitation equipment is not necessary. These features, along with the simple extraction of MS from PPM medium, make this new methodology robust, reliable and consistent. We also demonstrates that the obtained MS are perfectly 
viable and consequently can be used for pathogenicity studies, epidemiological and biocontrol tests.

\section{Reference}

Akash, M. S. H., \& Rehman, K. (2015). Recent progress in biomedical applications of pluronic (PF127): Pharmaceutical perspectives. Journal of Controlled Release, 209, 120-138. https://doi.org/10.1016/j.jconrel.2015.04.032

Bercea, M., Darie, R. N., Nit, L. E., \& Morariu, S. (2011). Temperature Responsive Gels Based on Pluronic F127 and Poly (vinyl alcohol), 4199-4206.

Bhat, R. G., \& Subbarao, K. V. (2007). Host Range Specificity in Verticillium dahliae. Phytopathology, 89(12), 1218-1225.https://doi.org/10.1094/phyto.1999.89.12.1218

Bilodeau, G. J., Koike, S. T., Uribe, P., \& Martin, F. N. (2012). Development of an assay for rapid detection and quantification of Verticillium dahliae in soil. Phytopathology, 102(3), 331-343. https://doi.org/10.1094/PHYTO-05-11-0130

Bohorquez, M., Koch, C., Trygstad, T., \& Pandit, N. (1999). A Study of the Temperat ure-Dependent Micellization of Pluronic F127. Journal of Colloid and Interface Science, 216, 34-40.

Botseas, D. D., \& Rowe, R. C. (1994). Development of potato early dying in response to infection by 2 pathotypes of Verticillium dahliae and coinfection by Pratylenchus penetrans. Phytopathology, 84, 275-282.

Butterfield, E. J., \& DeVay, J. E. (1977). Reassessment of Soil Assays for Verticillium dahliae. Phytopathology. https://doi.org/10.1094/Phyto-67-1073

Chet, I., \& Henis, Y. (1975). Sclerotial Morphogenesis in Fungi. Annual Review of Phytopathology, 169-192. https://doi.org/10.1146/annurev.py.13.090175.001125 
225 Declerck, S., Strullu, D. G., and Fortin, A. (eds). (2005). In Vitro Culture of Mycorrhizas. Berlin: Springer Science \& Business Media. doi: 10.1007/b138925

Devay, J. E., Forreste, L., Garber, R. H., \& Butterfi, E. (1974). Characteristics and concentration of propagules of Verticillium dahliae in air-dried field soils in relation to prevalence of Verticillium wilt in cotton. Phytopathology, 64, 22-29.

Enebe, M. C., \& Babalola, O. O. (2019). The impact of microbes in the orchestration of plants' resistance to biotic stress: a disease management approach. Applied Microbiology and Biotechnology, 103(1), 9-25. https://doi.org/10.1007/s00253$018-9433-3$

Fan, R., Klosterman, S. J., Wang, C., Subbarao, K. V., Xu, X., Shang, W., \& Hu, X. (2017). Vayg1 is required for microsclerotium formation and melanin production in Verticillium dahliae. Fungal Genetics and Biology. https://doi.org/10.1016/j.fgb.2016.11.003

Fradin, E. F., \& Thomma, B. P. H. J. (2006). Physiology and molecular aspects of

Gwon, K., Jo, E. J., Sahu, A., Lee, J. Y., Kim, M. G., \& Tae, G. (2018). Improved near infrared-mediated hydrogel formation using diacrylated Pluronic F127-coated upconversion nanoparticles. Materials Science and Engineering C, 90(July 2017), 77-84. https://doi.org/10.1016/j.msec.2018.04.029

Harrison, J. A. C., \& Isaac, I. (1969). Survival of the causal agents of early dying disease (Verticillium wilt) of potatoes. Annals of Applied Biology, 63(2), 277-288. https://doi.org/10.1111/j.1744-7348.1969.tb05489.x

Hawke, M. A., \& Lazarovits, G. (1994). Production and manipulation of individual microsclerotia of Verticillium dahliae for use in studies of survival. Phytopathology. 
Hu, X., Bai, Y., Chen, T., Hu, D., Yang, J., \& Xu, X. (2013). An optimized method for in vitro production of Verticillium dahliae microsclerotia. European Journal of Plant Pathology. https://doi.org/10.1007/s10658-013-0170-2

Jackson, M. A., \& Payne, A. R. (2016). Microbial-Based Biopesticides, 1477, 71-83. https://doi.org/10.1007/978-1-4939-6367-6

Jeong, C. S., Chakrabarty, D., Hahn, E. J., Lee, H. L., \& Paek, K. Y. (2006). Effects of oxygen, carbon dioxide and ethylene on growth and bioactive compound production in bioreactor culture of ginseng adventitious roots. Biochemical Engineering Journal, 27(3), 252-263.

Keykhasaber, M., Thomma, B. P. H. J., \& Hiemstra, J. A. (2018). Verticillium wilt caused by Verticillium dahliae in woody plants with emphasis on olive and shade trees. European Journal of Plant Pathology, 150(1), 21-37. https://doi.org/10.1007/s10658-017-1273-y

Klebahn, H. (1913). Beiträge zur Kenntnis der Fungi imperfecti.

Klosterman, S. J., Atallah, Z. K., Vallad, G. E., \& Subbarao, K. V. (2009). Diversity, Pathogenicity, and Management of Verticillium Species. Annual Review of Phytopathology. https://doi.org/10.1146/annurev-phyto-080508-081748

Lee, S. B., Milgroom, M. G., \& Taylor, J. W. (1988). A rapid, high yield mini-prep method for isolation of total genomic DNA from fungi. Fungal Genetics Reports, $35(1), 23$.

Li, C., Zhou, X., Lewis, E. E., Yu, Y., \& Wang, C. (2019). Study on host-seeking behavior and chemotaxis of entomopathogenic nematodes using Pluronic F-127 gel. Journal of Invertebrate Pathology, 161, 54-60. https://doi.org/10.1016/j.jip.2019.01.004

López-Escudero, F. J., Mwanza, C., \& Blanco-López, M. A. (2006). Production of homogeneous and viable Verticillium dahliae microsclerotia effective for 
Verticillium wilt studies. Biotechnology, 5(4), 421-428.

276

277

López-Escudero, F. J., \& Blanco-López, M. A. (2007). Relationship Between the Inoculum Density of Verticillium dahliae and the Progress of Verticillium Wilt of Olive. Plant Disease, 91(11), 1372-1378. https://doi.org/10.1094/PDIS-91-11-1372

Lv, C., Su, Y., Wang, Y., Ma, X., Sun, Q., \& Jiang, Z. (2007). Enhanced permeation performance of cellulose acetate ultrafiltration membrane by incorporation of Pluronic F127. Journal of membrane science, 294(1-2), 68-74.

Malandraki, I., Tjamos, S. E., Pantelides, I. S., \& Paplomatas, E. J. (2008). Thermal inactivation of compost suppressiveness implicates possible biological factors in disease management. Biological Control, 44(2), 180-187. https://doi.org/10.1016/j.biocontrol.2007.10.006

Mercado-Blanco, J., Rodriguez-Jurado, D., Pérez-Artés, E., \& Jiménez-Díaz, R. M. (2001). Detection of the nondefoliating pathotype of Verticillium dahliae in infected olive plants by nested PCR. Plant Pathology, 50(D), 609-619. https://doi.org/10.1016/j.fcr.2012.07.020

Mol, L. (1995). Effect of plant-roots on the germination of microsclerotia of Verticillium dahliae. 2. Quantitativeanalysis of the luring effect of crops. European Journal of Plant Pathology, 101, 679-685.

Nadakavukaren, M. J., \& Horner, C. E. (1959). An alcohol agar medium selective for determining Verticillium-microsclerotia in soilTitle. Phytopathology, 49, 527-528.

Sánchez-Martín, J., \& Keller, B. (2019). Contribution of recent technological advances to future resistance breeding. Theoretical and Applied Genetics, (0123456789). https://doi.org/10.1007/s00122-019-03297-1

Sarmiento-Villamil, J. L., Prieto, P., Klosterman, S. J., \& García-Pedrajas, M. D. (2018). Characterization of two homeodomain transcription factors with critical but distinct 

roles in virulence in the vascular pathogen Verticillium dahliae. Molecular Plant Pathology, 19(4), 986-1004. https://doi.org/10.1111/mpp.12584

Schnathorst, W. C. (1981). Life cycle and epidemiology of Verticillium. Fungal Wilt Diseases of Plants, 82 .

Short, D. P. G., Sandoya, G., Vallad, G. E., Koike, S. T., Xiao, C.-L., Wu, B.-M., Subbarao, K. V. (2015). Dynamics of Verticillium Species Microsclerotia in Field Soils in Response to Fumigation, Cropping Patterns, and Flooding. Phytopathology, 105(5), 638-645. https://doi.org/10.1094/PHYTO-09-14-0259-R

Qiu, Y. R., Rahman, N. A., \& Matsuyama, H. (2008). Preparation of hydrophilic poly (vinyl butyral)/Pluronic F127 blend hollow fiber membrane via thermally induced phase separation. Separation and Purification Technology, 61(1), 1-8.

Varo, A., Raya-Ortega, M. C., \& Trapero, A. (2016). Enhanced production of microsclerotia in recalcitrant Verticillium dahliae isolates and its use for inoculation of olive plants. Journal of Applied Microbiology. https://doi.org/10.1111/jam.13167

Wang, H., Williams, G. R., Wu, J., Wu, J., Niu, S., Xie, X., ... Zhu, L. M. (2019). Pluronic F127-based micelles for tumor-targeted bufalin delivery. International Journal of Pharmaceutics, 559, 289-298. https://doi.org/10.1016/j.ijpharm.2019.01.049

Wheeler, D. L., \& Johnson, D. A. (2016). Verticillium dahliae Infects, Alters Plant Biomass, and Produces Inoculum on Rotation Crops. Phytopathology, 106(6), 602613. https://doi.org/10.1094/PHYTO-07-15-0174-R

Wu, B., Takeshita, N., Wu, Y., Vijayavenkataraman, S., Ho, K. Y., Lu, W. F., \& Fuh, J. Y. H. (2018). Pluronic F127 blended polycaprolactone scaffolds via e-jetting for esophageal tissue engineering. Journal of Materials Science: Materials in Medicine, 29(9). https://doi.org/10.1007/s10856-018-6148-z 
324 Wu, Z. H., Wang, T. H., Huang, W., \& Qu, Y. B. (2001). A simplified method for chromosome DNA preparation from filamentous fungi. Mycosystema, 20(4), 575.

\section{$327 \quad$ Figure legends}

Fig.1 Growth and microsclerotia formation of Verticillium dahliae after 15 days of incubation at $24{ }^{\circ} \mathrm{C}$ in the dark: (A) PDA culture media and (B) PPM culture media Fig.2 Observation to optical microscope Leica model DM 750, of the germination of microsclerotia of $V$. dahliae in PDA culture medium. Each MS was able to form fungal colonies, (A) Objective Hi Plan 4 x /0.10, (B) Objective Hi Plan 10 x / 0.25, (C) Objective Hi Plan 40 x /0.65.

Fig.3 Result of the PCR. 1-2: non-infected tomato plants (negative control); 3-4-5-6: plants inoculated with MS from $V$. dahliae; 7: Internal Control: 8: mycelium of V.dahliae (positive control); 9: molecular marker 
bioRxiv preprint doi: https://doi.org/10.1101/635276; this version posted May 10, 2019. The copyright holder for this preprint (which was not certified by peer review) is the author/funder. All rights reserved. No reuse allowed without permission.

\section{$349 \quad$ Figure 1.}

(A)

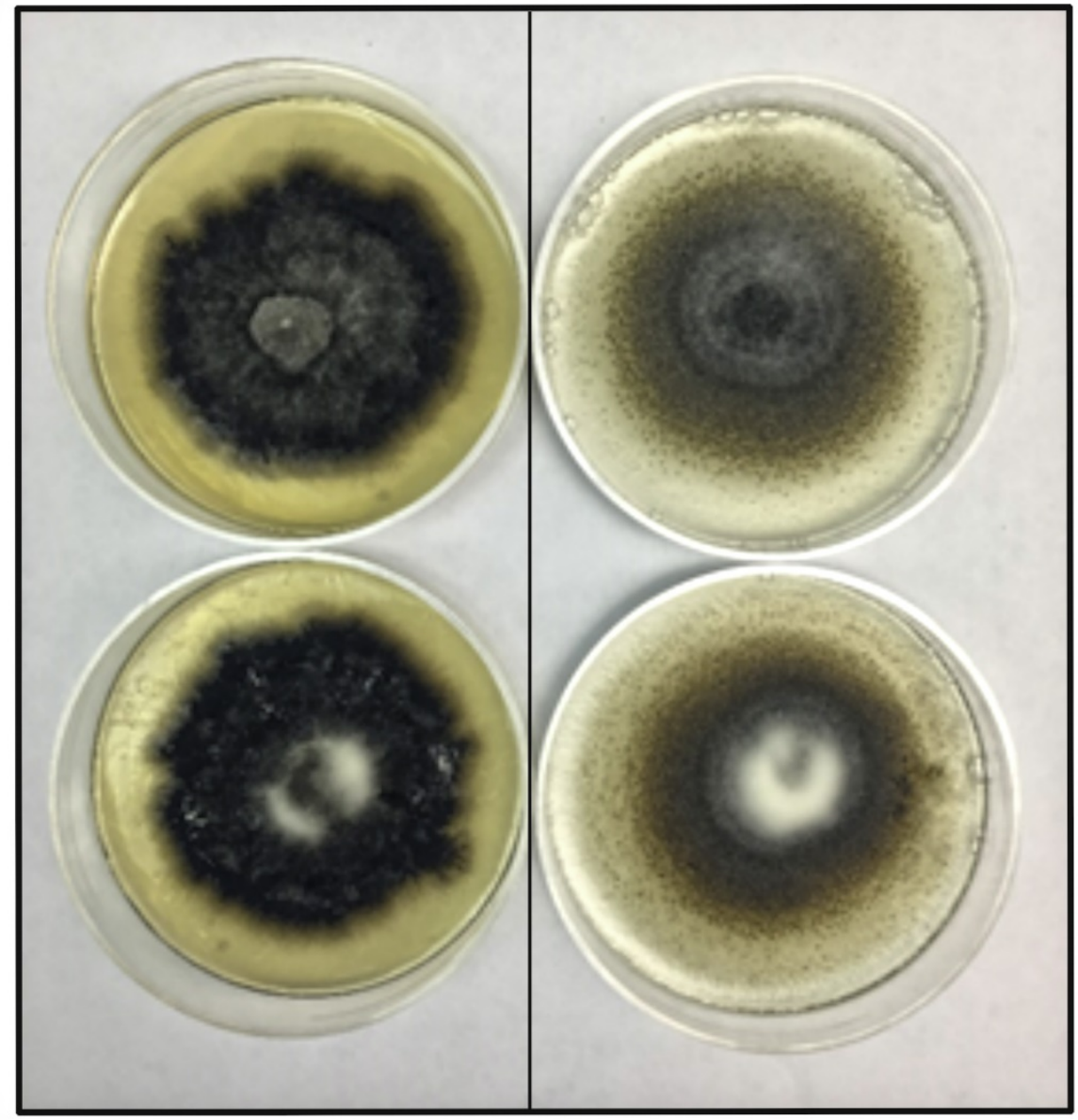

(B) 
bioRxiv preprint doi: https://doi.org/10.1101/635276; this version posted May 10, 2019. The copyright holder for this preprint (which was not certified by peer review) is the author/funder. All rights reserved. No reuse allowed without permission.

\section{$358 \quad$ Figure 2.}

(A)

(B)

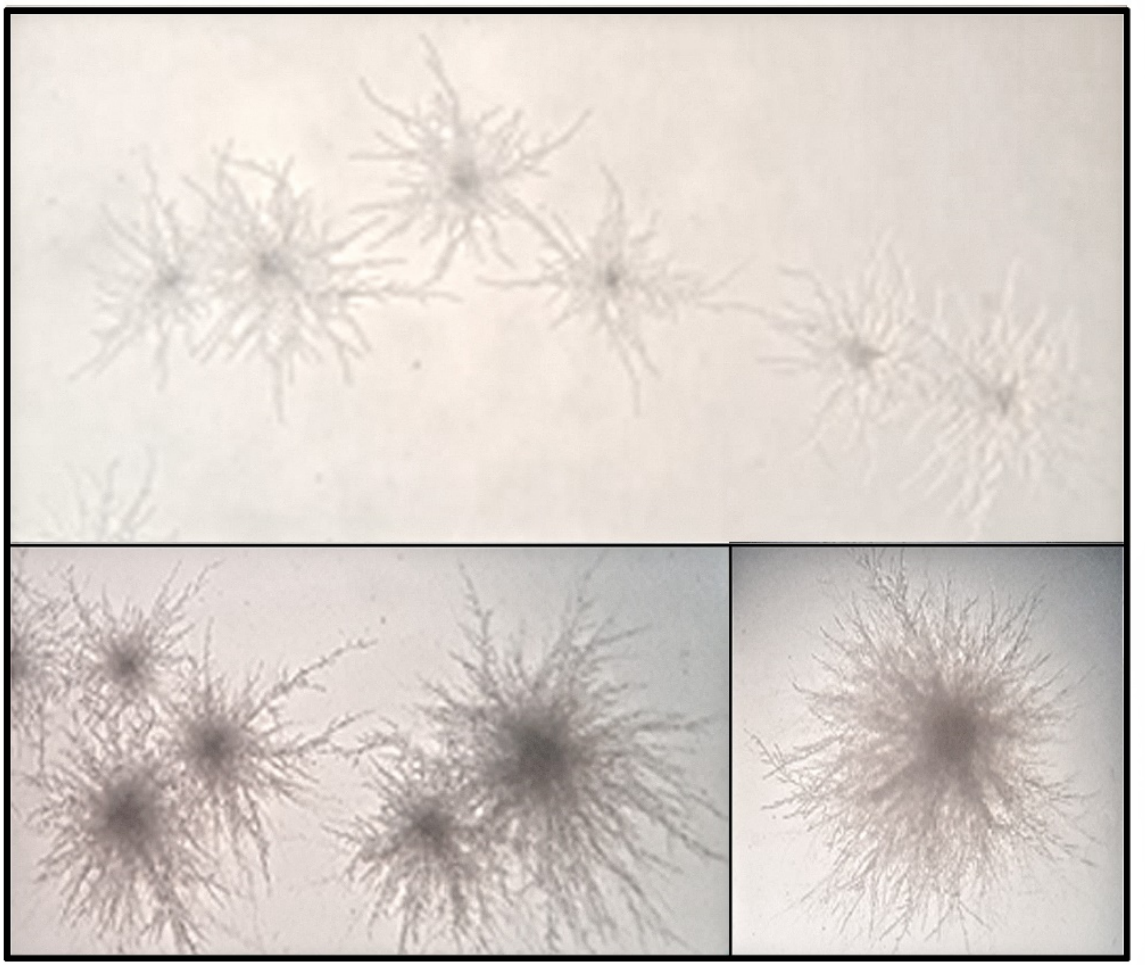

(C) 
bioRxiv preprint doi: https://doi.org/10.1101/635276; this version posted May 10, 2019. The copyright holder for this preprint (which was not certified by peer review) is the author/funder. All rights reserved. No reuse allowed without permission.

\section{$370 \quad$ Figure 3.}

